Marquette University

e-Publications@Marquette

College of Nursing Faculty Research and

Publications

Nursing, College of

$9-2020$

\title{
“No One Could Calm Him Down”: Mothers' Experience of Autism Diagnosis and Obtainment of Resources in an Urban Public School District
}

Norah L. Johnson

Marquette University, norah.johnson@marquette.edu

Phonethip Sangasy

Marquette University

Karen Marie Robinson

Marquette University, karen.robinson@marquette.edu

Follow this and additional works at: https://epublications.marquette.edu/nursing_fac

Part of the Nursing Commons

\section{Recommended Citation}

Johnson, Norah L.; Sangasy, Phonethip; and Robinson, Karen Marie, "'No One Could Calm Him Down": Mothers' Experience of Autism Diagnosis and Obtainment of Resources in an Urban Public School District" (2020). College of Nursing Faculty Research and Publications. 803.

https://epublications.marquette.edu/nursing_fac/803 
Marquette University

e-Publications@Marquette

\section{Nursing Faculty Research and Publications/College of Nursing}

This paper is NOT THE PUBLISHED VERSION; but the author's final, peer-reviewed manuscript. The published version may be accessed by following the link in the citation below.

Families, Systems, \& Health, Vol. 38, No. 3 (September 2020): 255-264. DOI. This article is (C) American Psychiatric Association and permission has been granted for this version to appear in e-

Publications@Marquette. American Psychiatric Association does not grant permission for this article to be further copied/distributed or hosted elsewhere without express permission from American Psychiatric Association.

\section{"No One Could Calm Him Down": Mothers' Experience of Autism Diagnosis and Obtainment of Resources in an Urban Public School District}

\section{Norah Johnson}

College of Nursing, Marquette University;

\section{Phonethip Sangasy}

College of Nursing, Marquette University

\section{Karen Robinson}

College of Nursing, Marquette University

In this study, we explored the experience of accessing diagnosis and resources in a Midwest urban public school district for mothers of children with autism spectrum disorder (ASD). ASD is a collective term for persistent social communication and social interaction challenges and restricted, repetitive 
patterns of behavior, interests, or activities listed in the Diagnostic and Statistical Manual of Mental Disorders, Fifth Edition (American Psychiatric Association, 2013). The prevalence of White children diagnosed with ASD (17.2 per 1,000) is higher than African American children (16 per 1,000) and Hispanic children (14 per 1,000; Centers for Disease Control and Prevention, 2018), with African American children receiving the ASD diagnosis on average 2-3 years later than their White or Hispanic peers (Kerfeld, Hoffman, Ciol, \& Kartin, 2011; Magaña, Lopez, Aguinaga, \& Morton, 2013; ValicentiMcDermott, Hottinger, Seijo, \& Shulman, 2012; Zuckerman, Sinche, Mejia, Cobian, Becker \& Nicolaidis, 2014).

Reasons for the inconsistency in ASD diagnosis are multifaceted. Low income, education levels, and cultural beliefs for African American and Hispanic families are barriers to accessing diagnosis and resources (Magaña et al., 2013; Voelkel, LeCroy, Williams, \& Holschuh, 2013; Zuckerman et al., 2014). Parents of children with ASD are reported to reduce work or stop working because of the care needs of the child, thus limiting their income (Child and Adolescent Health Measurement Initiative, 2013). Hispanic parents may be hesitant to seek care and services for their child, feeling shame or embarrassment due to the stigma of mental disabilities within their community (Burkett, Morris, Manning-Courtney, Anthony, \& Shambley-Ebron, 2015; Zuckerman et al., 2014). There is also a shortage of child focused psychologists, developmental pediatricians, child psychiatrists, and advanced practice nurses with the expertise in developmental and behavioral health to diagnose ASD (Bridgemohan et al., 2018). Thus, some children only receive a school-based/educational determination of ASD based upon the Individuals With Disabilities Education Act (2004) requirements (see Figure 1).

For a student to meet the educational eligibility for ASD, the Individual Education Plan (IEP) team must determine that the impairment adversely affects a student's learning and educational performance. Educational performance may include:

- Cognitive performance, including academic and pre-academic skills.

- Communication skills.

- Personal/Social skills.

- Sensory processing and motor planning skills.

- Adaptive skill, including self-help skills and activities of daily living.

The impact on the educational performance may carry over to the home enviroment. For example, the student could have difficulty with home work that impacts academic performance.

Figure 1. Educational evaluation guide for autism spectrum disorder (ASD).

An educational determination of ASD alone is less favorable than also receiving a medical diagnosis of ASD, based on application of the Diagnostic and Statistical Manual of Mental Disorders criteria, developmental history, and structured observation (American Psychological Association, 2013). Medical diagnosis gives parents the opportunity to pursue additional therapeutic interventions, such as behavior therapy, speech therapy, occupational therapy, individual counseling, or medication intervention to treat symptoms associated with ASD. Forty-six states and the District of Columbia have 
laws that require insurance coverage of autism services for people with a medical diagnosis of ASD (National Conference of State Legislatures, 2018).

The two most common services received by students with an educational determination of ASDs are speech/language and occupational therapies at school (Wei, Wagner, Christiano, Shattuck, \& Yu, 2014). In contrast, lower rates of students have a behavior management plan to learn impulse control and social skills in schools (Wei et al., 2014). On average, parents of children with ASD use seven to nine therapies outside of the schools to treat symptoms of ASD (Wei et al., 2014). Children without the medical diagnosis of ASD do not qualify for insurance reimbursement for services not offered outside of school and many of these services are not provided for free at school.

In the school environment, mothers have experienced stress and stigma related to their child's behavior and a lack of understanding and empathy from school staff (Gill \& Liamputtong, 2011). While many public school districts have specialists in development and behavior (i.e., school psychologists), teachers may be too overwhelmed to understand and implement interventions for behavior that is out of their range of expertise (Cassady, 2011; Friedlander, 2010). Understanding the experiences of parents through their own personal narratives is vital to creating strategies to reduce the barriers and challenges they face when seeking care for their children (Holloway \& Freshwater, 2007). The purpose of this study was to explore the experience of accessing autism diagnosis and resources in a Midwest urban public school district for diverse mothers of children with ASD.

\section{Method}

\section{Participants}

This study included one focus group held at an urban autism summit with nine mothers of a child between the ages of 5 and 21 years who are diagnosed with ASD in the same public school district. Criteria for inclusion in this study included (a) must be the legal parent/guardian of a child with a medical diagnosis and/or educational determination of ASD and (b) must have a child with ASD who is currently enrolled in a school in the Inner City School District. There were no specific exclusion criteria. The small size of the focus group allowed for an in-depth discussion in a comfortable setting on parental experiences and their perceptions on barriers to care and access to resources outside of school.

\section{Procedure}

After receiving Institutional Review Board approval from Marquette University, the approved flyers were distributed through the local Autism Society. Prior to beginning the focus group session, the participants read and signed the consent forms and filled out a demographic survey and a questionnaire on resource use. Participants were instructed to identify resources they used now or in the past from a list of 33 available resources for persons with ASD noted in a local ASD resource guide. Examples of resources on the list included: applied behavior analysis, aquatic therapy, music therapy, speech/language therapy, support group, recreational summer camps, and respite.

Two researchers led the audio recorded discussion using a structured question guide (see Figure 2). All nine mothers received a $\$ 10$ gift card to thank them for their time. 
1. Think back to before your child was diagnosed with autism. What were your concerns? What were your challenges?

2. Tell me about your experience of getting the autism diagnosis for your child?

3. Can you tell me about the resources/services that you and your child received in school? Outside of school?

4. How would you describe your experience with school/health professionals before, during, and after the diagnosis?

5. What has helped you the most? What has helped you the least?

Figure 2. Focus group question guide.

\section{Data Analysis}

The narrative inquiry method (Holloway \& Freshwater, 2007) was used to analyze the data from the transcripts into themes of attributed meaning to the mothers' experiences. Narratives describe the participants' motivation for their behaviors by capturing the thoughts, feelings, emotions, and reasons for their actions (Holloway \& Freshwater, 2007). The process of sharing stories in the small groups facilitated the participants' ability to give meaning to their experiences (Holloway \& Freshwater, 2007). Narratives provided others an opportunity to understand the lived experiences of those individuals through their interpretations (Holloway \& Freshwater, 2007).

Specifically, the researchers read for themes representing the meanings the participants attributed to the behaviors of the people they came in contact with throughout the process of autism diagnosis and interactions with school personnel. Common words and phrases were labeled and the themes and subthemes were first discerned by individual members of the research team. Next, the researchers met in person and compared the interpretations of the transcription. They discussed the initial differences, the rationale, and the supporting quotations from the transcriptions until they reached consensus on the themes and subthemes from the narratives as an iterative process.

\section{Credibility and Trustworthiness}

Credibility and trustworthiness of the data were supported by the audio recording of the focus group and verbatim transcription by one of the researchers. Two of the three researchers were present at the focus group. The researchers educational backgrounds varied (pediatric nurse practitioner, midwife, biomedical sciences), as did their race and ethnicity (White, Black, Hmong). As a collaborative team, the researchers discussed the role that past experiences had on the identification of the themes and the interpretation of the data from the transcripts.

\section{Results}

Three themes resulted from analysis of the mother's narratives on the attributed meanings to their experience: (a) late diagnosis, (b) negative communication experiences, and (c) coping strategies. Subthemes and exemplar quotations follow the demographics and results of the outside resources survey below. 


\section{Demographics}

The demographics of the participants and their child with ASD are displayed in Table 1. All nine participants were married mothers of boys diagnosed with ASD. The mothers identified as African American (56\%, $n=5)$, Latina $(22 \%, n=2)$, and White $(22 \%, n=2)$, with an annual income below $\$ 61,000$. Fifty-six percent $(n=5)$ of mothers had at least a high school degree, and $44 \%(n=4)$ had a bachelor's degree or higher. The mean age of child diagnosis was 6 years old (range $=2-15$ years). Four children (44\%) received different diagnoses prior to the ASD diagnosis (e.g., attentiondeficit/hyperactivity disorder, mood disorders, stuttering, anxiety, depression, or severe retardation). Mothers of six children reported that their child had both a medical diagnosis of ASD from a clinic and a school-based determination of ASD, while the other three mothers reported that their child only had a school-based determination of ASD.

Table 1 Mother and Child Demographics ( $N=9)$

\begin{tabular}{|l|l|}
\hline Demographic & $n(\%)$ \\
\hline Mother & \\
\hline Gender (female) & $9(100)$ \\
\hline Age, years & \\
\hline $25-34$ & $1(11)$ \\
\hline $35-44$ & $3(33)$ \\
\hline $45-54$ & $4(44)$ \\
\hline $55-64$ & $1(11)$ \\
\hline Marital status (married) & $9(100)$ \\
\hline Race & \\
\hline White (non-Hispanic) & $2(22)$ \\
\hline Hispanic & $2(22)$ \\
\hline African American & $5(56)$ \\
\hline Highest degree & \\
\hline High school/GED & $1(11)$ \\
\hline Some college, no degree & $4(44)$ \\
\hline Bachelor & $2(22)$ \\
\hline Master & $2(22)$ \\
\hline Income & \\
\hline$\leq \$ 20,000$ & $2(22)$ \\
\hline \$21,000-40,000 & $3(33)$ \\
\hline \$41,000-60,000 & $0(0)$ \\
\hline$>$ \$60,000 & $2(22)$ \\
\hline Unanswered & $2(22)$ \\
\hline Child & \\
\hline Gender (male) & $9(100)$ \\
\hline Age of early indications of ASD, years & \\
\hline$\leq 1$ & $2(22)$ \\
\hline $1-3$ & $6(67)$ \\
\hline $3-6$ & $1(11)$ \\
\hline
\end{tabular}




\begin{tabular}{|c|l|}
\hline Age of diagnosis, years & \\
\hline $1-5$ & $4(44)$ \\
\hline $6-10$ & $3(33)$ \\
\hline $11-15$ & $2(22)$ \\
\hline First diagnosis & \\
\hline ASD only & $5(56)$ \\
\hline Non-ASD & $4(44)$ \\
\hline
\end{tabular}

Note. ASD = autism spectrum disorder.

${ }^{a}$ Attention-deficit/hyperactivity disorder, mood disorders, stuttering, anxiety, depression, or severe retardation.

\section{Outside Resources}

Table 2 presents the types of resources that the mothers and their children with ASD are receiving outside of school. Six of the nine mothers indicated that they were currently receiving resources outside of school. However, only $27 \%$ (9 of 33) of possible resources and services listed in the survey were reported to be used. The resource used the most was Title 19 Medicaid insurance by $33 \%(n=3)$ of the mothers, while the second highest was respite, recreational summer camp and social skills classes at $22 \%(n=2)$ for each resource.

Table 2. Mother's Resource Use Outside of School $(N=9)$

\begin{tabular}{|l|l|}
\hline Resource & $n(\%)$ \\
\hline Katie Beckett T-19 insurance & $3(33)$ \\
\hline Respite & $2(22)$ \\
\hline Recreational summer camp & $2(22)$ \\
\hline Behavioral therapy & $1(11)$ \\
\hline Social skills class & $2(22)$ \\
\hline Psychotherapy & $1(11)$ \\
\hline Aquatic therapy & $1(11)$ \\
\hline Daily living skills & $1(11)$ \\
\hline Assistive technology & $1(11)$ \\
\hline
\end{tabular}

\section{Themes}

\section{Late diagnosis}

\section{Problems that parents didn't perceive as signs of ASD}

Five mothers mentioned what they had observed about their child's behaviors, as well as what others had noticed, which they did not recognize as signs of ASD: One mother stated that "One of the therapists noticed something about him doing things like spinning in the floor or mimicking like a puppet in his hands, with his hands . . . I didn't think anything of it at the time." A second mother noted that her child had trouble sleeping but did not know it was a sign of autism. She stated, "I was up-the type to be up at 3:30 in the morning to go to work and he still be up watching TV. I was like 'Go to sleep.'" A third mother reported that her son had trouble when he started school. "He couldn't go into the classroom, he couldn't sit there, he could not listen, he couldn't do what you were expected to do in a school setting." 
Two mothers commented on the activity level of their child. One mother stated that

at about 1.5-2 years he hit the terrible two's and it seemed that he would never get out of them. He would get inordinately upset at small things, and take a while to calm down. Our baby sitter noticed it too.

Another mother remembered her son was not active enough. She stated,

... really quiet and a nice little boy if I sat him down with his toys. He would just be looking out the window, looking at his toys, he never touched the toys at all . . . (he) never cry and he never spoke until he was 5 or 6 years old.

\section{Making comparisons to other siblings or children}

One mother stated that she knew something was wrong: "[He] is our second child, so we knew that this was just not quite right." Additionally, two other mothers shared that, prior to receiving the autism diagnosis, they would compare their child's behaviors and developmental stages to another sibling or younger relative. One mother said, "My niece was doing all these things and he was not. Um, he didn't really have ... eye contact with us ... nor did he play with her. Um he mostly was to himself." Another mother stated,

He was just so quiet like sometimes you just see him laying down just looking up, and he was like, maybe 6 months old and I'm like "oh he's so good" . . . And uh, you know I didn't, no, we didn't connect it.

She went into further details about the comparisons she made between her son and daughter as they got older: "When his sister was three (years old) ... she didn't have the same symptoms or the same behavior patterns as he did. Like she spoke a lot, she was so social so I thought, okay maybe there is something going on...."

Negative communication experiences

\section{Husband and wife}

Mothers reported facing hardships alone with the lack of support from their husbands. One mother expressed her feelings about her husband while she was dealing with her son's problems: "I was a first time mom and my husband wasn't any help." Another mother discussed how she and her husband felt when they tried dealing with their son's meltdowns: "No one knew how to calm him down, dad get mad, and it's like, you get mad and angry at him, it just makes it worse and, we didn't know how to calm him down."

\section{Parent-educational professional}

The mothers addressed the negative communication experiences with educational professionals extensively. One of the three mothers commented on the lack of shared decision making with school professionals regarding one of the services for her child with ASD:

Some of the things that were listed in his IEP (Individual Education Plan) that he was supposed to get was like occupational therapy but at one school, they decided among themselves that they were not gonna give it to him.

One mother shared personal examples about school professionals. She stated, 
Not once did they ever mention autism. They said he's developmentally delayed. I need you to come in to an IEP meeting and sign off on this. I said no. Nothing was really explained. They would tell me if you don't sign the IEP, your son cannot continue to be in school full day, you have to pick him up at noon. . . so, I said (expletive) it. I took him out of school and I kept him at home until he was five.

Communicating with the schools on the telephone was an issue for two of the three mothers. After unreturned telephone calls they reported going to the school in person. A mother shared one of her experiences with the lack of communication from her son's school: "I would call the school so many times trying to get somebody to get back ... they would be on the defense and I wouldn't get anywhere ... so ... I got him out of there."

One mother perceived a lack of communication from school and their reaction to her constant phone calls. She reported that she felt she was sacrificing her personal time to take care of her son at school: "I'm calling up there all the time. They think I'm the troublemaker. . . I I started volunteering at school every day so I could watch over my son." Another mother also found herself giving up her time to take care of her son at school: "We can't get off work. There's been so many occasions I've had to run to the school on my lunch hour."

One of the mothers shared how she perceived she fought with the school to obtain one of the resources for her child with ASD: "In school he also would have, um, OT, occupational therapy, because he couldn't hold the scissors and I had to fight them for that." Another mother shared her success with obtaining the IEP for her son with ASD: "It took us three years to get him that IEP. They kept saying no he's fine. Until he started acting up in class. And I knew it was gonna happen. It was just a matter of time."

Mothers discussed their feelings and perceptions about teachers' intentions to help children with ASD, which sparked two different viewpoints. This quote portrays one point of view about teachers' best intentions: "They have had the best intentions ... I think in many cases, they want to help, they want to make accommodations ..."Another mother agreed: "I think there's best of intentions." Another mother stated, "They got good intentions. Uh, but when they have all the pressures from everywhere else, my boy's gonna get left between the cracks or whatever unless I'm advocating and I know you all know, it's tiring." Another mother stated, "But if we did not wear out bossy boots in many different colors ... what happens to the kids whose parents don't know."

One of the other mothers noted that her personal experience led her to doubt that teachers have the best intentions. She stated, "Unfortunately I haven't had that experience where I believed they have the best intentions ... so, the easiest route is to remove your child, or to have them go to another class, or somewhere else." She also addressed what she thought it meant for someone to have good intentions: "If you have the best intentions, then you're gonna advocate no matter what your resources are, the limitations on them"

Coping strategies

Resources

A total of five mothers shared information on the resources and strategies they used to help them, as well as their child, cope with the challenges they faced. One mother noted that "My family support 
group, being able to um, vent, and uh, finding resources on the Internet on how to handle, um, stress, the stressors at home with the children, I mean with the schools, complaints."

Three of the five mothers mentioned specific resources in addition to the "resources used" questionnaire, including extended school year and recreation. "It's (recreation's) just wonderful. He's not bored, he does swimming, [and] they go on field trips." Two mothers noted the use of other recreation/theater groups:

I know (theater group name) has been huge for us. That's my safe place. They also have a program called Next Steps. And they don't turn anyone away for financial reasons ... you have to fill out an application but l've never been turned away for a need.

Another mother described what she liked about another local program with the following statement: "I love taking him there because they-they don't judge him, they don't take personal what he may do or say, they know how to deal with meltdowns."

\section{Prayer}

One of the mothers shared that she uses prayer to help her cope with her challenges as the other mothers voiced equal sentiments regarding church and religion. She stated, "I don't want to step boundaries over anybody's religious beliefs, but prayer. ..." Another mother interrupted her to agree by stating, "Oh yeah." A third mother noted, "MH and church" while a fourth mother said, "Prayer did a lot. It did I mean ..." Three mothers interrupted her and quickly added their agreement: "Yes I believe that church. .. ," "For me, I second that," and

Locking myself in the bathroom, $\mathrm{y}^{\prime}$ know, to take five minutes. And then I used to pray this prayer ... to pray to take the stress off of him and put it on me ... (and) for God to put people, positive people, in our pathway.

\section{Discussion}

We identified three themes capturing the meanings that the mothers attributed to their child's ASD diagnosis and access and use of resources. The mothers attributed the late diagnosis to various issues. The meanings for the first theme, late diagnosis, reflects current literature on barriers to care. Mothers missed signs of ASD and did not think of it much until someone else pointed out the symptoms or until they started comparing their child's development to other siblings and younger relatives. This oversight was related to the lack of knowledge of the symptoms of ASD, which often delay diagnosis of ASD in children (Voelkel et al., 2013; Zuckerman et al., 2014). Some of the children were diagnosed with other disabilities and medical issues such as ADHD, mood disorders, stuttering, anxiety, depression, and severe retardation. Misdiagnosis by professionals who lack the training and experience with ASD patients contributes to uncertainty in ASD prevalence among children, specifically minority children as well as diagnostic delay, which affects eligibility for certain services, such as the Birth to Three Program (Kerfeld et al., 2011; Valicenti-McDermott et al., 2012). The Birth to Three Program is a federally mandated Early Intervention program designed to help children with developmental delays or disabilities during the first 3 years of life to improve health outcomes (U.S. Department of Education, n.d. a). 
Implicit bias, that is, unintentional prejudice and stereotyping, may have contributed to the difficulties mothers' experienced in interacting with the schools. Como, Florindez, Tran, Cermak, and Stein Duker (2019) reported that implicit biases might be held by health care providers and manifest in language when health care language includes microaggressions, marginalization, and preconceptions, highlighting biases about patients (Como et al., 2019). Professionals might unconsciously use language that could negatively impact patient-provider rapport and increase stigma the already marginalized population of mothers of children with ASD and may effect quality of care (Como et al., 2019).

Nonacceptance of ASD within certain schools and communities resulted in a few parents removing their children and acting on their own to find the best resources and environment for their child to thrive in. The stigma of developmental disabilities and the lack of acceptance of ASD in communities seemed to drive families to take power into their own hands to inform their community and spread awareness (Burkett et al., 2015). However, this action also contributed to negative communication experiences between parents and educational professionals. Because some parents/mothers may have not heard of ASD, the communication between the assessment team at the school must be sensitive and supportive so that the parent acts on the recommendations of the assessment team and does not remove the child from the resources at the school that are intended to help the child have the best developmental outcomes.

The second theme, negative communication experiences, reflects current literature on the mothers' perception on the lack of parent-school partnership and the lack of husband-wife communication and support. Mothers in this study went into detail about their experiences of difficulties with the school. The mothers shared that they were left out of decision-making regarding their child's services, which resulted in their perceived need to fight with the schools for those services. In addition, the general education teachers and administrators were perceived by mothers as refusing to collaborate with them, advocate for, or assist in providing services that their child with ASD needed for growth, development, and academic success. Parents are legally part of the IEP for children with disabilities (U.S. Department of Education, n.d. b). The mothers' narratives highlighted a disconnect between this legal requirement and the mothers' perception of the poor procedural and interpersonal approaches of the school personnel. Evidence from recent studies suggests that poor communication, denial of services, and exclusion from decision-making causes parents to fight for services, advocate for their children, and develop an "us versus them" attitude (Burkett et al., 2015; Jolles, Lee, \& Javier, 2018; Magaña, Parish, Rose, Timberlake, \& Swaine, 2012). Many mothers of children with disabilities take advocating for their child beyond the family to the level of activist roles outside of the family (Keenan, Dillenburger, Doherty, Byrne, \& Gallagher, 2010).

The mothers from the focus group expressed their desire to establish a parent-school partnership to share their stories, perspectives, and challenges with school professionals who lacks the training, experience, and knowledge to work with children with ASD. A few of the mothers briefly mentioned their husbands during the discussion regarding the time before and during their child's diagnosis. One mother described her husband negatively during the diagnostic process. Another mother commented that her husband gets angry whenever their son has a meltdown. The final mother mentioned that her husband was indifferent after their son received the ASD diagnosis. Little detail is known about the quality of their marital life but one study found that husbands either tend to discredit mothers' 
concerns, be uncooperative with the diagnostic process, or take a passive role in their child's care (Zuckerman et al., 2014). Such reactions place burden on mothers to navigate the diagnosis and treatment for their child with symptoms of ASD.

Lastly, various coping strategies were used by mothers to relieve stress and to obtain resources for their children with ASD. Outside resources are important for behavior management and social skills training not offered in schools. Programs that had an accepting, nonjudgmental environment run by people with ASD knowledge and training were highly preferred by the mothers. Professionals or groups that are culturally insensitive or judgmental widen the gap in relationship and trust with parents (Burkett et al., 2015; Magaña et al., 2012). Programs and services that did not turn parents away due to financial reasons were also favorable. One study found that families struggle to pay for quality services due to financial barriers and poor insurance coverage (Sansosti, Lavik, \& Sansosti, 2012). Training existing school nurses in pediatric mental health could better support children and families. In the present study, religion and prayer also played an important role with coping with stress. This finding matches past research finding that spirituality and religious coping are salient factors in resilience for parents of children with ASD, contributing to family quality of life (Ekas, Whitman, \& Shivers, 2009; Gardiner, Mâsse, \& larocci, 2019). Thus, the awareness of ASD in communities and churches should be prioritized as well to reduce stigma and empower families to seek resources for their child with ASD, and welcome parents and children at churches (Johnson \& Van Hecke, 2015). Only six of the nine students in the present study had medical diagnosis of ASD, and six listed they used outside resources, often requiring this medical diagnosis. The number of resources they accessed was lower that than the reported average of seven to nine therapies outside of the schools to treat symptoms of ASD used by a typical parent of a child with ASD (Wei et al., 2014).

\section{Limitations}

This study has limitations. The sociodemographic make-up of the participants, both in terms of race/ethnicity and income likely contributed to experiences unique to these groups. Although the mothers of the focus group expressed their experiences and difficulties with communicating with school professionals and caring for a child with ASD, their experiences may not be generalized for other families of children with ASD given the small sample size. Data on resource use at school was not collected. The perspective of teachers, school health care providers, fathers and Spanish speaking parents was not presented.

\section{Conclusion}

This study is one small but important step toward assessing and planning access to resources for economically disadvantaged inner-city families of children with ASD, who receive late diagnosis of ASD and are challenged to communicate successfully with school personnel. These barriers may be related to implicit biases on the part of providers and school personnel. This needs to be studied. The mothers' narratives indicated a strong need for advocacy and parent-school partnership. Future research could build on this study by assessing the perspectives of teachers and school nurses, and compare gender differences between the experiences and perceptions of fathers and mothers on access to resources and diagnosis for their children with ASD. Spanish-speaking families of children with ASD should also be 
recruited to learn more about the meanings they attribute to their experiences and perceptions of ASD diagnosis and access to resources.

\section{References}

American Psychiatric Association. (2013). Diagnostic and statistical manual of mental disorders (5th ed.). Arlington, VA: Author.

Bridgemohan, C., Bauer, N. S., Nielsen, B. A., DeBattista, A., Ruch-Ross, H. S., Paul, L. B., \& Roizen, N. (2018). A Workforce Survey on Developmental-Behavioral Pediatrics. Pediatrics, 141, e20172164. 10.1542/peds.2017-2164

Burkett, K., Morris, E., Manning-Courtney, P., Anthony, J., \& Shambley-Ebron, D. (2015). African American families on autism diagnosis and treatment: The influence of culture. Journal of Autism and Developmental Disorders, 45, 3244-3254. 10.1007/s10803-015-2482-x

Cassady, J. M. (2011). Teachers' attitudes toward the inclusion of students with autism and emotional behavioral disorder. Electronic Journal for Inclusive Education, 2(7), 5.

Centers for Disease Control and Prevention. (2018). Community report on autism. Retrieved from https://www.cdc.gov/ncbddd/autism/addm-community-report/differences-inchildren.html

Child and Adolescent Health Measurement Initiative. (2013). National profile of children with special health care needs and autism spectrum disorders: Key findings from the 2009/10 NS-CSHCN and 2011/12 NSCH. Retrieved from https://www.childhealthdata.org/docs/drc/asd-data-brief 7-30-13.pdf

Como, D. H., Florindez, L. I., Tran, C. F., Cermak, S. A., \& Stein Duker, L. I. (2019). Examining unconscious bias embedded in provider language regarding children with autism. Nursing \& Health Sciences, 22, 197-204.

Ekas, N. V., Whitman, T. L., \& Shivers, C. (2009). Religiosity, spirituality, and socioemotional functioning in mothers of children with autism spectrum disorder. Journal of Autism and Developmental Disorders, 39, 706-719. 10.1007/s10803-008-0673-4

Friedlander, D. (2010). "Sam comes to school": Including students with autism in your classroom. The Clearing House, 82, 141-144. 10.3200/TCHS.82.3.141-144

Gardiner, E., Mâsse, L. C., \& larocci, G. (2019). A psychometric study of the Family Resilience Assessment Scale among families of children with autism spectrum disorder. Health and Quality of Life Outcomes, 17, 45. 10.1186/s12955-019-1117-x

Gill, J., \& Liamputtong, P. (2011). Being the mother of a child with Asperger's syndrome: Women's experiences of stigma. Health Care for Women International, 32, 708-722. 10.1080/07399332.2011.555830

Holloway, I., \& Freshwater, D. (2007). Narrative research in nursing. Oxford, United Kingdom: Blackwell.

Individuals With Disabilities Educational Act. (2004). Sec. 300.8 Child with a disability. Retrieved from http://idea.ed.gov/explore/view/p/,root,regs,300,A,300\%252E8

Johnson, N., \& Van Hecke, A. (2015). Increasing autism awareness in inner-city churches: A brief report. Journal of Pediatric Nursing, 30, e63-e69. 10.1016/j.pedn.2015.04.008

Jolles, M. P., Lee, P. J., \& Javier, J. R. (2018). Shared decision-making and parental experiences with health services to meet their child's special health care needs: Racial and ethnic disparities. Patient Education and Counseling, 101, 1753-1760. 10.1016/j.pec.2018.05.022

Keenan, M., Dillenburger, K., Doherty, A., Byrne, T., \& Gallagher, S. (2010). The experiences of parents during diagnosis and forward planning for children with autism spectrum disorder. Journal of Applied Research in Intellectual Disabilities, 23, 390-397. 10.1111/j.1468-3148.2010.00555.x

Kerfeld, C. I., Hoffman, J. M., Ciol, M. A., \& Kartin, D. (2011). Delayed or forgone care and dissatisfaction with care for children with special health care needs: The role of perceived cultural competency of health care providers. Maternal and Child Health Journal, 15, 487-496. 10.1007/s10995-010-0598-3

Magaña, S., Lopez, K., Aguinaga, A., \& Morton, H. (2013). Access to diagnosis and treatment services among Latino children with autism spectrum disorders. Intellectual and Developmental Disabilities, 51, 141153. 10.1352/1934-9556-51.3.141 
Magaña, S., Parish, S. L., Rose, R. A., Timberlake, M., \& Swaine, J. G. (2012). Racial and ethnic disparities in quality of health care among children with autism and other developmental disabilities. Intellectual and Developmental Disabilities, 50, 287-299. 10.1352/1934-9556-50.4.287

National Conference of State Legislatures. (2018). Autism and insurance coverage state laws. Retrieved from https://www.ncsl.org/research/health/autism-and-insurance-coverage-state-laws.aspx\#1

Sansosti, F. J., Lavik, K. B., \& Sansosti, J. M. (2012). Family experiences through the autism diagnostic process. Focus on Autism and Other Developmental Disabilities, 27, 81-92. 10.1177/1088357612446860

U.S. Department of Education. (n.d.a). IDEA Individuals With Disabilities in Education Act Part C. Retrieved from https://sites.ed.gov/idea/regs/c

U.S. Department of Education. (n.d.b). IDEA Individuals With Disabilities in Education Act Sec. 300.322: Parent participation. Retrieved from https://sites.ed.gov/idea/regs/b/d/300.322

Valicenti-McDermott, M., Hottinger, K., Seijo, R., \& Shulman, L. (2012). Age at diagnosis of autism spectrum disorders. The Journal of Pediatrics, 161, 554-556. 10.1016/j.jpeds.2012.05.012

Voelkel, H., LeCroy, C. W., Williams, L. R., \& Holschuh, J. (2013). The full spectrum. Best Practices in Mental Health, 9, 31-46.

Wei, X., Wagner, M., Christiano, E. R., Shattuck, P., \& Yu, J. W. (2014). Special education services received by students with autism spectrum disorders from preschool through high school. The Journal of Special Education, 48, 167-179. 10.1177/0022466913483576

Zuckerman, K. E., Sinche, B., Mejia, A., Cobian, M., Becker, T., \& Nicolaidis, C. (2014). Latino parents' perspectives on barriers to autism diagnosis. Academic Pediatrics, 14, 301-308.

10.1016/j.acap.2013.12.004 